\title{
A formação do leitor no contexto da desinformação e das fake news: desafios para os estudos de letramentos na pandemia da covid-19 e além ${ }^{1}$
}

\author{
Juliana Alves Assis* \\ Fabiana Komesu** \\ Marie-Christine Pollet***
}

Em março de 2018, Vosoughi, Roy e Aral, pesquisadores do Media Lab do Massachusetts Institute of Tecnology (MIT), apresentaram um estudo na Science, em que discutiam notícias verdadeiras e falsas postadas na rede social Twitter e avaliadas por seis agências independentes de checagem de fatos, no período de 2006 a 2017. O conjunto do material era formado de 126 mil tuítes em língua inglesa, espalhados quatro milhões e meio de vezes por três milhões de pessoas. Os temas checados por aquelas agências e investigados pelos autores, em período anterior à pandemia da covid- 19,2 eram diversos e versavam sobre política, negócios, entretenimento, ciência, desastres naturais, dentre outros. Os autores chegaram à conclusão de que

\footnotetext{
* Professora doutora do Programa de Pós-graduação em Letras da PUC Minas. ORCID: https://orcid.org/0000-0002-9383-4850.

** Professora doutora do Programa de Pós-graduação em Estudos Linguísticos da Unesp. ORCID: https://orcid.org/0000-00023820-1559.

*** Professora doutora da Faculté de Lettres, Traduction et Communication da Université Libre de Bruxelles. ORCID: https://orcid. org/0000-0001-6421-3660

1 Este trabalho se vincula às ações dos projetos "Escrita acadêmica/escrita científica: das formas de presença do autor, do outro, das áreas de conhecimento e seus domínios disciplinares" (Chamada Universal MCTIC/CNPq 2018, processo 434902/2018-7) e "Literacies in Different Fields of Knowledge" (Programa CAPES-PrInt-Unesp, processo CAPES/AUXPE no. $88887.310463 / 2018-00)$.

2 covid-19 é acrônimo de Corona Virus Disease, sendo 19 a referência ao ano de 2019, de quando datam os primeiros registros da doença. É uma enfermidade de espectro clínico variável, de casos assintomáticos a sintomas gripais, chegando a provocar pneumonia grave e problemas respiratórios que podem levar à morte. Atualmente, há variantes mais transmissíveis e letais, em circulação no Brasil e no mundo (disponível em: https://coronavirus.saude.gov.br/sobre-a-doenca. Acesso em: 17 ago. 2021).
} 
um post verdadeiro atinge em média mil pessoas; uma notícia falsa, entretanto, pode atingir entre mil e 100 mil pessoas. Observaram ainda que a probabilidade de uma notícia falsa ser retransmitida é 70\% maior do que uma notícia verdadeira e que, para temas relacionados à política, essa porcentagem aumenta. Ainda segundo os autores, o fator "novidade" da informação é o elemento diferenciador na disseminação de notícias, em meio à urgência de seu compartilhamento em mídias digitais, comunicadores instantâneos e outros meios. Dizem os autores:

\begin{abstract}
"Quando a informação é nova, é não apenas surpreendente, mas também mais valiosa - tanto de um ponto de vista da teoria da informação (oferece mais ajuda para tomada de decisão), quanto de um ponto de vista social (veicula um status social daquele que 'está por dentro' ou tem acesso a 'informações privilegiadas').” (VOSOUGHI; ROY; ARAL, 2018, p. $4) .^{3}$
\end{abstract}

Em língua inglesa, utiliza-se firehosing, expressão derivada de "mangueira de incêndio", quando se quer fazer referência à "disseminação de uma informação, que pode ser mentirosa, em um fluxo constante, repetitivo, rápido e em larga escala." (MELLO, 2020). Destacamos nessa alegoria dois aspectos que parecem relevantes numa reflexão sobre informações verdadeiras, falsas ou enganosas, num contexto digital em que práticas sociais de leitura e de escrita são levadas em conta: (1) devido ao amplo alcance e à vazão da "mangueira de incêndio" - em razão, portanto, dos modos de circulação, disseminação, propagação e compartilhamento na internet -, o "bombeiro" - um produtor/criador de conteúdo de internet - pode manter

\footnotetext{
3 No original: "When information is novel, it is not only surprising, but also more valuable -- both from an information theory perspective (it provides the greatest aid to decision-making), and from a social perspective (it conveys social status that one is 'in the know,' or has access to unique 'inside' information).” (VOSOUGHI; ROY; ARAL, 2018, p. 4).
} 
uma distância do local onde se encontra o incêndio - dito de outro modo, o produtor/criador pode manter anonimato e não ser identificado, tampouco responsabilizado pela produção textual e pelas consequências de sua disseminação -; (2) mangueiras contra incêndio potencializam o jato d'água, com alta pressão e velocidade, numa ampla cobertura de área - com essa força, celeridade e abrangência, o leitor, usuário direto ou indireto de mídias digitais, é o alvo a ser atingido, uma vez que a ele se atribuiu o acolhimento (ou recusa, reprovação) de notícias falsas ou enganosas, na troca, compartilhamento e edição de textos numa "cultura da conexão" por meio de mídias propagáveis (JENKINS, GREEN, FORD, 2014). As metáforas e associações empregadas nessa descrição revelam tanto a potência quanto a periculosidade da informação falsa ou enganosa nas mídias digitais.

O estudo de Vosoughi, Roy e Aral foi publicado em 2018, numa época em que já muito se discutiam os efeitos dessa propagação de notícias falsas ou enganosas e de seu alcance, considerando seu impacto em dimensões como a política, em eventos como Brexit, no Reino Unido, e em processos eleitorais de países como Estados Unidos, Índia, Indonésia e Brasil, como discutido por autores como Wardle e Derakhshan (2017), Castells (2018), Miguel (2019) e Mello (2020). Benkler, Faris e Roberts (2018, p. 275) avaliam, por exemplo, a relevância da utilização de técnicas de ponta na análise de dados de plataformas digitais, como a realizada pela empresa de comunicação Cambridge Analytica, no fornecimento de insights sobre a preferência do público e a produção de estratégias de persuasão em temas como ideologia política, profundamente arraigados em sentimentos e 
emoções. ${ }^{4}$ Se a pesquisa do MIT fosse refeita em 2020 ou adiante, teria de se voltar ainda para os efeitos da desinformação e fake news no contexto da covid-19, dada não apenas a gravidade da doença em si e as consequências de movimentos antivacina (da covid-19 e outras doenças) em diferentes partes do mundo, mas também o fato de que o acesso do leitor e usuário de mídias digitais a informações qualificadas e fundamentadas, em tempo certo e em linguagem acessível ao público leitor, é considerado elemento diferenciador na qualidade de vida dos cidadãos, no domínio da saúde e além, ${ }^{5}$ como recomendado pelos Objetivos de Desenvolvimento Sustentável (ODS) da Agenda 2030 da Organização das Nações Unidas (ONU), particularmente, os ODS 3 ("Saúde e bem-estar”) na associação com o 4 ("Educação de qualidade"). ${ }^{6}$

Em março de 2021, a Organização Pan-Americana da Saúde (OPAS) publicou um guia para auxiliar países das Américas a formular uma estratégia de comunicação de riscos com relação às vacinas contra a covid-19, preocupada em transmitir à população - portanto, aos cidadãos leitores, usuários diretos ou indiretos de mídias digitais e outros meios de comunicação - "todas as informações sobre o processo de imunização, desde os testes clínicos e a produção de novas vacinas até a adoção, distribuição e priorização de grupos aos quais serão administradas uma ou mais vacinas $[. .$.$] , bem como sobre o acesso universal às vacinas$ [...].” (OPAS, 2021, p. 2). ${ }^{7}$ A OPAS entende que o fortalecimento

4 Zuboff (2020, p. 269) chama de renderização (rendition) as operações que transformam a experiência humana em dataficação, isto é, que convertem padrões de comportamento de consumo e dados pessoais, apresentados como valor de troca em plataformas digitais que se anunciam como gratuitas, em dados utilizados por empresas, companhias e instituições as mais diversas.

5 A afirmação de consenso social sobre a transparência das informações parece partir, entretanto, de uma concepção de linguagem segundo a qual a comunicação entre os sujeitos se daria de forma sempre explícita e direta, destituída de interesse social. Discutimos adiante essa concepção e suas implicações para o processo de produção dos sentidos da linguagem.

6 Disponível em: https://brasil.un.org/pt-br/sdgs. Acesso em: 20 ago. 2021.

7 Disponível em: https://iris.paho.org/bit
pdf?sequence=5\&isAllowed=y. Acesso em: 20 ago. 2021. 
das capacidades de comunicação e o planejamento de ministérios e secretarias de saúde são de fundamental relevância para o enfrentamento da covid-19 nas Américas, dado o excesso de informações em circulação, em meio a certa percepção pública sobre segurança de produtos médicos, com dúvidas e desconfiança da população quanto às vacinas contra a covid-19, numa conjuntura em que figuram grupos antivacinas associados a líderes políticos e outros grupos sociais (OPAS, 2021, p. 7).

No ano anterior, a organização havia divulgado alerta sobre o processo de desinformação que se expandia, já naquele momento, de maneira acelerada, na disseminação de notícias falsas ou enganosas sobre o novo coronavírus. Naquele momento, a OPAS observou padrões de pesquisa em motores de busca, relacionados à procura de fontes confiáveis, de evidências de intervenções eficazes, de atualizações epidemiológicas, de comunicados gerais dos governos, de dados sobre casos e mortes confirmadas, de notícias locais e internacionais sobre a covid-19. Em levantamento realizado em março de 2020, contabilizou a produção de 550 milhões de tuítes com os termos "coronavirus", "corona vírus", "covid-19", "covid_19" ou "pandemic". ${ }^{8}$ Num período de 30 dias, foram carregados, segundo a OPAS, 361 milhões de vídeos no YouTube, com a classificação “Covid-19” ou "COVID 19"; foram identificados 19.200 artigos sobre o assunto no Google Acadêmico. Na avaliação da organização, como se pode concluir a partir da excessiva quantidade de informações divulgadas em curto período de tempo, apenas uma parte delas pode ser fidedigna e pode, pois, atender às expectativas de um leitor na busca de informação qualificada.

8 Disponível em: https://iris.paho.org/bitstream/handle/10665.2/52054/Factsheet-Infodemic_por.pdf?sequence=14. Acesso em: 20 ago. 2021. 
O problema da desinformação é concebido, de forma restrita, como notícias falsas verificáveis, as chamadas fake news. Esse termo tem sido, entretanto, evitado na literatura por pelo menos dois motivos. O primeiro, segundo estudiosos da Comissão Europeia (2018, p. 10), é que o emprego do termo fake news envolve não apenas notícias comprovadamente falsas e enganosas, mas também informações fabricadas, misturadas a fatos, que incluem de redes de seguidores falsos, vídeos fabricados ou manipulados por deepfake, trollagem organizada, memes, a publicidade direcionada e contas automatizadas para astroturfing - isto é, para contas que se utilizam de personalidades influentes, com publicação de posts em mídias digitais, veiculação em comerciais televisivos, segundo estratégias para influenciar a opinião pública, como se essas manifestações fossem decorrentes de uma ação procedente de apoio público e não de uma cooperação paga. O segundo motivo que tem justificado o descrédito está relacionado ao fato de que, para os estudiosos, o termo fake news tem sido apropriado por políticos e apoiadores que, ao terem sua atuação criticada por veículos de mídia, acusam os opositores de disseminar fake news, em ataque à liberdade de imprensa em sociedades democráticas (ver, entre outros, KAKUTANI, 2018; VISCARDI, 2020). Com base em pesquisa de Nielsen e Graves (2017), a Comissão Europeia (2018) observa que cidadãos têm frequentemente associado o termo a debate público partidário e a jornalismo de má qualidade, em vez de correlacioná-lo a práticas de desinformação.

Por esses motivos, a expressão fake news tem sido preterida e, em seu lugar, desinformação, em concepção ampla, tem sido utilizada não apenas para fazer referência a informações verificáveis, mas também a estratégias de fabricação e 
manipulação de notícias; estratégias de produção do verossímil em certas atividades de publicidade e propaganda que exploram os limites do verossímil para constituírem o valor de troca, por exemplo, de uma mercadoria; ou, ainda, a estratégias de linguagem como a sátira e a paródia, como discutido pelos especialistas da Comissão Europeia (2018) citados e outros como Wardle e Derakhshan (2017), Martens et al. (2018), Pangrazio (2018), Tandoc Jr., Lim e Ling (2018). Sabidamente, trata-se de recursos que se definem pela exploração dos limites da verossimilhança na linguagem. Essas diferentes estratégias, discutem os autores, produziriam no leitor de mídias digitais (e também de outros suportes) dificuldades no reconhecimento de propósitos comunicativos, com consequências para o processo de produção de sentidos entre os sujeitos da linguagem e a tomada de decisões em diferentes esferas, como as já citadas da política e da saúde.

Do ponto de vista dos estudos de letramentos, como discutido por Komesu, Alexandre e Silva (2020, p. 197-198), a assunção de uma concepção ampla de desinformação permite problematizar a prevalência de uma concepção de linguagem em que essa desordem informacional, outro termo utilizado na literatura para tratar do fenômeno, é deslocada para o eixo de uma ordem segundo a qual haveria inteligibilidade, clareza ou nitidez em relação ao que cada sujeito diria ao outro. Essa condição de transparência da linguagem é tomada por muitos como ideal, uma vez que produziria tranquilidade e bem-estar resultantes da obediência a leis, como as de convivência ética entre os cidadãos. No funcionamento das mídias digitais, trata-se de o leitor poder receber uma informação de um familiar sobre, por exemplo, outras drogas terapêuticas no tratamento precoce 
da covid-19, e interpretá-la unicamente como uma atenção, um cuidado que essa pessoa próxima estaria compartilhando, ${ }^{9}$ em vez de avaliá-la na qualidade de um clickbait, estratégia amplamente utilizada na internet para gerar tráfego, por meio de conteúdos sensacionalistas, para sites que monetizam o espaço com publicidade paga. ${ }^{10}$ Títulos como "10 razões pelas quais...", "X coisas que você deve saber...", "Agora você pode...", "Veja como a cidade X..." são tomados como eficazes para atrair a atenção do leitor asfixiado pelo volume e pela velocidade de recebimento de informações (firehosing), sob condições afligentes de uma doença cujo vírus transmissor se encontra em constante mutação.

No momento em que países estão em processo de vacinação contra a covid-19, notícias falsas ou enganosas sobre a vacina são amplamente propagadas. Numa delas, há um alerta de que vacinas anticovid teriam metais tóxicos e transformariam os pacientes em antenas $5 \mathrm{G}$ ambulantes. Numa pesquisa simples com os termos "vaccine" e "5G antenna" no motor de busca do Google ainda era possível encontrar mais de 667 mil resultados (até 22/8/2021). Em março de 2021, quando a pandemia já durava um ano em diferentes países, chegaram a mais de 2.200.000 resultados. Essa "notícia" da associação entre a vacina e antenas $5 \mathrm{G}$ foi amplamente disseminada em diversas localidades do mundo e está entre as desmentidas pelo serviço de checagem de fatos da Organização Mundial da Saúde

\footnotetext{
9 Galhardi et al. (2020, p. 4205) mostram, em estudo realizado no período de 17/3 a 10/4/2020, com dados extraídos do WhatsApp, Facebook e Instagram, a prevalência de compartilhamento de "informações" desse tipo. No período inicial da pandemia no Brasil, "notícias" (falsas ou enganosas, no entanto), sobre métodos caseiros de prevenção eram $65 \%$ do conjunto analisado e métodos caseiros de cura, 20\%. Foi constatado ainda o compartilhamento de notícias falsas sobre golpes bancários $(5,7 \%)$, golpes/arrecadações para instituições de pesquisa $(5 \%)$ e a veiculação de que a covid-19 seria uma estratégia política $(4,3 \%)$.

10 Ver, a esse respeito, Benkler, Faris e Roberts (2018, p. 279 e ss.), sobre utilização de clickbait no período de eleições norteamericanas.
} 

desafios para os estudos de letramentos na pandemia da covid-19 e além

(OMS), dedicado ao combate de fake news sobre a covid-19. ${ }^{11}$

Embora alguns imunizantes possam ter traços de metais, não há doses significativas em sua composição e não há relação entre a tecnologia da "internet das coisas" e vacinas anticovid. ${ }^{12}$ Por que fake news como essa e tantas outras - vacinas teriam objetivo de implantar chip no cérebro humano, poderiam levar à contaminação por HIV, provocar câncer, causar autismo, levar à mudança de sexo, para citar apenas algumas - são amplamente disseminadas e também acolhidas em práticas sociais de leitura e escrita que envolvem, de maneira direta ou indireta, uso de tecnologias digitais?

A resposta não é evidente. No cerne, reconhece-se o leitor, padecente, direta ou indiretamente, de uma doença que contabilizava, até 22/8/2021, 211.728.725 casos de contaminados e 4.429.474 mortos no mundo, segundo dados da universidade norte-americana Johns Hopkins (JHU). O Brasil aparecia naquele momento como o segundo país em número de mortos (574.209, antecedido pelos Estados Unidos, com 628.408) e o terceiro em número de casos (20.556.487; atrás dos Estados Unidos, com 37.696.161, e da Índia, com 32.424.234 infectados), também segundo dados da JHU. ${ }^{13}$ A vacinação, de fundamental importância para o controle da transmissão da doença nas populações, teve início em dezembro de 2020 em diferentes países. No mundo, 4.920.008.655 doses tinham sido administradas até 22/8/2021, conforme dados da JHU. No Brasil, até 20/8/2021, 121.263 .020 pessoas, o equivalente a $57,27 \%$ da população, tinham recebido a primeira dose da

\footnotetext{
11 Disponível em: https://www.who.int/emergencies/diseases/novel-coronavirus-2019/advice-for-public/myth-busters\#5g. Acesso em: 22 ago. 2021.

12 Disponível em: https://veja.abril.com.br/blog/diario-da-vacina/as-principais-fake-news-relacionadas-a-vacina-de-vaga-lumesas-bitcoins/. Acesso em: 22 ago. 2021.

13 Disponível em: https://coronavirus.jhu.edu/map.html. Acesso em: 22 ago. 2021.
} 
vacina; 54.001.078 pessoas estavam imunizadas com as duas doses ou dose única, o equivalente a $25,5 \%$ da população, de acordo com o Consórcio de Veículos de Imprensa do Brasil, a partir de dados de Secretarias Estaduais de Saúde. ${ }^{14} \mathrm{O}$ projeto Our World in Data, ligado à Universidade de Oxford, indicava, em 21/8/2021, que 32,4\% da população mundial havia recebido pelo menos uma dose da vacina contra covid-19 e 24,4\%, duas doses ou dose única. Portugal tinha vacinado, até aquela data, $79,34 \%$ da população $(67,44 \%$ com duas doses ou dose única); o Reino Unido, 70,08\% da população $(61,13 \%$ com duas doses ou dose única); os Estados Unidos, 60,18\% da população (50,95\% com duas doses ou dose única). Dados da Nigéria mostravam, entretanto, que $1,24 \%$ da população tinha sido vacinada $(0,69 \%$ com duas doses ou dose única); na Tanzânia, apenas $0,37 \%,{ }^{15} \mathrm{o}$ que expõe desigualdade (anterior à pandemia) e os desafios de conter o avanço da disseminação de variantes do vírus enquanto não houver vacina para todos no planeta.

O leitor, em contato direto ou indireto com mídias digitais, não é indiferente aos efeitos da covid-19 na família, no sistema de saúde, na educação, ${ }^{16}$ na economia, seja por aprovação ou rejeição das medidas institucionalmente impostas nesse período. Tampouco é indiferente ao problema da desinformação e das fake news. Em termos de comportamento de consumo de notícias e informação, relatório do Reuters Institute (NEWMAN et al., 2021, p. 8-9), realizado com base numa pesquisa em 46 mercados

\footnotetext{
14 Disponível em: https://especiais.g1.globo.com/bemestar/vacina/2021/mapa-brasil-vacina-covid/. Acesso em: 22 ago. 2021. O consórcio é formado pelos veículos de imprensa Extra, Folha de S.Paulo, G1, O Estado de S. Paulo, O Globo e UOL do Brasil. Divulga os dados com base nos seguintes critérios: (1) número de vacinados informado diariamente por secretarias estaduais de Saúde; (2) percentual de vacinados, informado por governos estaduais sobre a população total; (3) total de doses recebidas pelos estados, segundo informações das secretarias estaduais.

15 Disponível em: https://ourworldindata.org/covid-vaccinations. Acesso em: 22 ago. 2021.

16 No âmbito da educação, por exemplo, reflexões sobre os efeitos da covid-19 em práticas letradas acadêmicas podem ser encontradas em Assis, Komesu e Fluckiger (2020); Ribeiro e Vecchio (2020); Komesu, Alexandre e Silva (2020); Oliveira, Brasileiro e Assis (2020); Komesu, Daunay e Fluckiger (2021).
} 

desafios para os estudos de letramentos na pandemia da covid-19 e além

de consumo no mundo, mostra crescente preocupação com a desinformação no contexto da pandemia. Segundo o relatório, os que usam mídias digitais são mais propensos a dizer que foram expostos a informações enganosas sobre o coronavírus do que os não usuários. A pesquisa aponta que os maiores índices de preocupação estão na África (74\%), seguida pela América Latina (65\%), América do Norte (63\%), Ásia (59\%) e Europa (54\%) (NEWMAN et al., 2021, p. 20-21). De maneira geral, os níveis mais elevados de preocupação com a disseminação de desinformação estão associados a comportamento de atores políticos, como no Brasil e na Polônia (ambos com 41\%, enquanto a média mundial é de $29 \%$ ). No que respeita ao uso de plataformas digitais, o relatório mostra que o Facebook é visto como o principal canal de divulgação de informações falsas ou enganosas em quase todos os lugares do mundo, ainda que aplicativos de mensagens instantâneas como o WhatsApp sejam concebidos como problema mais grave em países como Brasil e Indonésia (35\% e 33\%, respectivamente) (NEWMAN et al., 2021, p. 22-23).

Komesu, Costa e Ciencia (no prelo) discutem a importância de problematizar a função do leitor no contexto da desinformação e das fake news, partindo da recomendação que fazem Wardle e Derakhshan(2017,p. 22), no âmbito dos estudos da Comunicação, a respeito do "intérprete" (ao lado do agente e da mensagem): qual ação foi tomada quando do recebimento da mensagem? Para Wardle e Derakhshan (2017 apud KOMESU, COSTA, CIENCIA, no prelo), "todos são editores em potencial", incluído o leitor. Komesu, Costa e Ciencia (no prelo, p. 7) avaliam, numa conjuntura de pós-verdade (McINTYRE, 2018), que a tentativa de o leitor autoconfirmar crenças e emoções numa cultura de 
compartilhamento e curtidas extrapola o que é considerado um posicionamento pessoal - resultante de habilidades individuais e cognitivas relacionadas a uma concepção de leitura como mera decodificação, como comentado adiante -; emerge numa conjuntura sócio-histórica que ressignifica determinadas práticas - portanto, determinados sentidos na produção da linguagem - em detrimento de outras. ${ }^{17}$ Não se trata, pois, do que o eu, individualmente, consegue ler ou interpretar, mas de condições sócio-históricas de produção que favorecem o processo de leitura e a emergência de determinados sentidos - contrariamente a outros, como discutido por estudiosos do discurso a partir, principalmente, de Foucault (2014), entre outros. Assim, num cenário pressuroso caracterizado, por um lado, pelo excesso de informação em circulação, por outro, por doença, morte, acesso pontual ou ausência de acesso à escola, desemprego, orientações desencontradas emitidas por líderes políticos, como no caso do Brasil, o que o leitor de mídias digitais consegue e pode ler, o que consegue compartilhar em mídias digitais não é resultante de opinião individual.

A atenção para o leitor se dá ao mesmo tempo em que não é possível controlar quem cria, produz, distribui a desinformação (WARDLE; DERAKHSHAN, 2017, p. 25-29) - como argumentado no caso de firehosing, segundo o qual o "bombeiro" (produtor/criador/distribuidor de conteúdo de internet) consegue manter distância do local (com anonimato) onde se encontra o "incêndio" (notícias falsas ou enganosas). Essa impossibilidade de controle sobre a produção dos sentidos (não restrita ao ambiente digital, mas nele colocada em evidência) acentua expectativas

\footnotetext{
17 Muito embora o efeito prevalente ainda seja o de um "poder afável", na expressão de Han (2018, retomada pelas autoras). Dito de outro modo, com Zuboff (2020, p. 270), não há consciência, nem mesmo consentimento dos sujeitos, de que dados pessoais estariam sendo compartilhados e utilizados para fins alheios, "um meio para a finalidade de outros", nas palavras da autora.
} 

desafios para os estudos de letramentos na pandemia da covid-19 e além

institucionais de que a formação acadêmico-científica poderia se constituir, como discutido por Komesu, Alexandre e Silva (2020, p. 202), num elemento diferenciador no enfrentamento à desinformação e às fake news, especialmente, na medida em que o letramento científico implicaria "a capacidade de [o sujeito] se envolver criticamente e tomar decisões sobre questões relacionadas à ciência, com base em informação" (SIAROVA; STERNADEL; SZÖNYI, 2019, p. 11, tradução dos autores).$^{18}$

Observa-se, nesses relatórios de organismos internacionais, uma preocupação com a autonomia que o sujeito teria ou poderá ter para, no momento de confronto com a enorme quantidade de informações online - caso dos 550 milhões de postagens no Twitter, 361 milhões de vídeos no YouTube, 19.200 artigos no Google Acadêmico sobre o novo coronavírus, identificados pela OPAS (2020) num único mês, ou ainda das mais de 667 mil páginas eletrônicas com menção a vacinas anticovid que teriam metais tóxicos e transformariam os pacientes em antenas $5 \mathrm{G}$ ambulantes -, fazer a escolha "certa" de distinguir a informação verdadeira da falsa ou enganosa. Da perspectiva dos estudos de linguagem, trata-se de uma concepção de subjetividade segundo a qual a responsabilidade pela produção dos sentidos estaria, sobremaneira, com o (no) leitor, como se o controle dessa produção dependesse exclusivamente de uma avaliação de cunho pessoal, feita por quem lê a notícia, e não das ditas condições que permitam ler e reconhecer o "verdadeiro" dos textos (FOUCAULT, 2014; PIOVEZANI; CURCINO; SARGENTINI, 2021).

Komesu, Costa e Ciencia (no prelo) consideram que o leitor de mídias digitais (mas não somente) não pode ser

18 No original: "the ability to engage critically with and make informed decisions about science-related issues". 
concebido como "decodificador passivo, cuja única habilidade se restringiria à interpretação de sinais gráficos da escrita e de outros constitutivos de textos multimodais". Tampouco seria aquele que intencionalmente escolhe o que pode e consegue ler ou editar. No âmbito dos estudos de letramentos, as autoras discutem que o traço de autonomia do leitor, comumente evocado, estaria próximo "a habilidades individuais de codificação e decodificação, como as reconhecidas pela instituição escolar". Ou ainda, para o que nos interessa discutir, às chamadas "habilidades de estudo", de ordem individual e cognitiva (LEA; STREET, 2014, p. 479), que trariam, em si, qualidades que lhes seriam inerentes, independentemente do que é escrito ou lido, por quem, para quem, em qual contexto. Permitiriam, como discutem os autores, a transferência do conhecimento de um contexto a outro, sem quaisquer problemas, supondo que a decodificação de uma língua bastasse para o processo de produção de sentidos.

O sujeito da linguagem aprende a ler e também a escrever já segundo uma aculturação e uma socialização acadêmica "quanto a discursos e gêneros baseados em temas e em disciplinas" (LEA; STREET, 2014, p. 479), que, por sua vez, respondem à "natureza institucional daquilo que conta como conhecimento em qualquer contexto acadêmico específico." (idem) - e fora desse contexto também -; respondendo, assim, a sistemas de valores que sustentam relações de dominação sobre quem sabe ler e escrever, para quem, segundo qual gênero discursivo, em qual contexto situado e em qual momento - excluindo-se, por conseguinte, quem não sabe. Trata-se, como diz Street (1984), de modelo ideológico de práticas e eventos em contextos situados, institucional e culturalmente dependentes do valor social da leitura e da escrita, atribuído por grupos que disputam entre si, 
por jogo de forças econômicas, religiosas e políticas, o que deve ser legitimado (ou não) como prática, com consequências para a educação formal e para outras práticas letradas vernaculares dos sujeitos (STREET, 2014). Desse modo, não existe prática social de leitura e escrita fora de um contexto situado (CORRÊA, 2004): não há fatos da língua fora de práticas sociais letradas/ orais.

No caso do leitor de mídias digitais, o acesso a informações científicas, médicas, filosóficas, artísticas, políticas, do mercado financeiro, entre tantas outras, em quantidade e em qualidade, ultrapassa a experiência empírica vivida pelo sujeito. McIntyre (2018, p. 35-36), dentre outros, problematiza, de um viés cognitivo, que esse processo de confrontação à profusão de informações, que ao sujeito podem não parecer ou ser verdadeiras, gera desconforto e tensão, constituindo, para o que nos interessa numa relação dos estudos de letramentos com os de discurso, uma ameaça à ilusão de centralidade da subjetividade, tal como discutido por Authier-Revuz (1990, p. 28) no que respeita à "função do desconhecimento do eu" e à "reconstrução de uma imagem de sujeito autônomo". Citando Freud e a "defesa do ego", McIntyre (2018, p. 35) observa que, nesse panorama da pós-verdade, o eu estaria sempre dotado de razão, independentemente da perspectiva que se assuma.

É como se o sujeito (escrevente, leitor) lidasse com a neutralidade da informação, segundo um modelo de letramento autônomo que prioriza a decodificação/codificação da língua(gem). Primeiramente, teria acesso à informação para apenas em seguida decidir o que dela fazer, como e o que interpretar/opinar/editar ou compartilhar nas mídias digitais, "desconhecendo" (na opacidade da linguagem) que a mera alusão 
à informação implica de imediato tomada de posição diante do exposto, o "atravessamento" de uma "exterioridade que está no interior do sujeito." (AUTHIER-REVUZ, 1990, p. 29). No âmbito dessa reflexão, o sujeito não "troca informação", mas lida com o jogo de efeitos de sentido do qual também é (e)feito (PÊCHEUX, 1990, p. 82-83), sob determinadas condições sócio-históricas (COURTINE, 2009) dos processos de produção particulares.

$\mathrm{O}$ uso de diferentes dispositivos digitais permitiria na contemporaneidade a busca da verdade na direção de uma transparência dos sentidos da linguagem. O sujeito da pósverdade não mais dependeria de determinadas instituições escola/universidade, Estado - para pesquisar e ter acesso ao conhecimento, não seria mais "subjugado por ideologias". Estaria livre para dizer/ler, segundo uma sua vontade individual, da maneira que considerar a verdadeira, desconsiderando como essa visão de autonomia é efeito de ideologias e da dependência de outras instituições. Parentes, amigos, conhecidos de grupos de plataformas digitais e aplicativos de comunicação instantânea, líderes religiosos, tornam-se, assim, fontes fidedignas porque, desprovidos de quaisquer credenciais técnicas ou acadêmicas, estariam supostamente também desprovidos de engajamento com interesses de outros grupos sociais - seriam imparciais, condição desejada nessa ilusão da subjetividade.

Segundo Roque (2020), é desse modo que "novos formadores de opinião conquistam seguidores e disputam a prerrogativa de influenciar o poder público" em mídias digitais, sem mediação de cientistas ou de quaisquer outros especialistas. No contexto da pandemia da covid-19 (mas também antes e além), não é suficiente que o leitor saiba a língua na qual a informação foi produzida (presumindo que o conhecimento de uma língua seja 
restrito à comentada codificação/decodificação). Ao receber, por exemplo, a "notícia” de que a "vacina 'chinesa' contém RNA replicável digitalizável" usado para "controlar a humanidade através de ondas que vai $[$ sic] emitir as antenas 5G", não é suficiente saber língua portuguesa para ler essa "notícia" que foi amplamente veiculada por WhatsApp no Brasil. Há um contexto de produção que condiciona a emergência desses sentidos, permitindo sua leitura (por adesão ou crítica). É preciso conseguir ler esse texto no diálogo com outros, característica da produção dos sentidos da linguagem. Essa intertextualidade em sentido amplo - portanto, essa interdiscursividade - necessariamente evoca a relação da linguagem com a história: da vacinação e também do avanço tecnológico (dos países asiáticos, com sinofobia), do conflito homem versus máquina.

Como discutido, o processo de leitura é ainda "atravessado" pelo índice de confiança que se tem em relação ao interlocutor (emissor imediato) da informação compartilhada. Num período de declínio da relação de confiança com as instituições, é o não especialista, diz Roque (2020), quem ganha destaque, como se a ausência de vínculo formal com determinados grupos pudesse implicar inexistência de interesses. Gestos e ações de atores públicos também (des)orientam práticas sociais de leitura em contexto digital (fora dele também), como observado no relatório do Reuters Institute (NEWMAN et al., 2021), em diversos países do mundo, e na nota técnica $n .^{\circ} 31$ da Rede de Pesquisa Solidária (2021), publicada no Brasil. Segundo a avaliação da equipe responsável pela nota técnica à época, o alcance dos ataques do Presidente da República e de outros políticos à CoronaVac, vacina produzida pelo Instituto Butantan em parceria com a farmacêutica chinesa Sinovac, pode afetar 
o processo de imunização contra a covid-19 no Brasil, com fortalecimento de grupos antivacina.

Por conseguinte, o processo de leitura, do enfrentamento da covid-19, da desinformação e das fake news é constituído de uma discussão pública sobre tomar ou não vacina, criticar ou não chineses, crer ou duvidar dos propósitos das instituições e da eficácia de métodos científicos. O leitor emerge de práticas discursivas de leitura, dos modos de circulação dos textos e seus suportes, de culturas disciplinares, segundo relações de poder e autoridade das sociedades (STREET, 1984, 2014). Assim, o que o leitor pode/consegue ler não é resultante de opinião pessoal ou da opinião dos que lhe são próximos, mas de "injunções que lhe foram impostas" (POSSENTI, 2010, p. 15) sócio-historicamente, mesmo de que maneira indireta.

O leitor não vive encerrado em "bolhas", como se pensa. O funcionamento das mídias digitais, na conjunção de uma governança algorítmica de bots e ciborgues - a exemplo do que é visto com influenciadores digitais que "aparecem" como sugestão nas páginas pessoais de mídias digitais e têm a conta movimentada por empresas, com seguidores pagos e likes programados, com comentários prontos de consentimento ou ainda de ataque a opiniões divergentes -, corrobora um efeito de estabilidade, de uma verdade alternativa que poderia ser a assumida pelo leitor. Essas práticas coexistem em conflito com outras, na interdiscursividade de teorias conspiratórias; declínio de mídias tradicionais; ataques a universidades e centros científicos legítimos; posicionamentos ideológicos dissimulados como controvérsia; falsa simetria na argumentação científica, com a ideia de que se deveria ouvir "os dois lados", quando há consenso científico e trabalho rigoroso de investigação em 
apenas um deles, restando ao outro a vivência empírica (ROQUE, 2020). A coerência interna de narrativas não fundamentadas ganha, assim, valor na pouca adesão à verdade que é tomada como exterior ao sujeito.

Estudiosos como Islam et al. (2020) recomendam que governos e outras agências devem investigar padrões de rumores, comentários estigmatizados e teorias da conspiração nas diferentes culturas, para desenvolver meios de comunicação apropriados ao enfrentamento da covid-19 nos respectivos países (ISLAM et al., 2020, p. 1627), com debate público e desenvolvimento orientado sobre os impactos das fake news e da desinformação (GALHARDI et al. 2020, p. 4208). No cerne dessas recomendações, está o leitor e uma formação que nada tem de individual, mas que demanda condições de leitura com o outro, na pluralidade, no diálogo e no debate público em que argumentos são apresentados e discutidos de maneira fundamentada, no reconhecimento da historicidade de que a linguagem é constituída e que permite ler criticamente a falsa conexão entre manchetes, ilustrações legendas, o falso contexto na manipulação de imagens, o conteúdo enganoso ou impostor, a fabricação de conteúdos no favorecimento de grupos. Ameaça, violência ou criminalização de pensamento divergente podem reprimir, mas não podem apagar as heterogeneidades da linguagem. A escola e a universidade têm um papel de destaque no enfrentamento da desinformação e das fake news e precisam de condições íntegras para o trabalho, enquanto mostram como a ciência e práticas científicas podem transformar fazeres e dizeres dos cotidianos.

Nesse sentido, escola e universidade se inscrevem como agentes importantes, frente aos desafios contemporâneos dos 
estudos de letramentos, com ênfase para o letramento crítico e o letramento científico. Na agenda do letramento crítico (GEE, 1994; McLAREN, 1998; FREIRE, 1987, 1996), o compromisso é com a formação do leitor crítico, condição imprescindível ao funcionamento da democracia, ao exercício da liberdade, ao estabelecimento da igualdade e da justiça social, condição que pressupõe o letramento científico, assumida a ciência como um relevante produto cultural da humanidade. $\mathrm{O}$ engajamento da população em relação à ciência bem como sua participação nas políticas públicas que definem as articulações prioritárias entre ciência, tecnologia e sociedade constituem parâmetros fundamentais para a educação científica (AYALA, 1996).

Tendo em conta tais defesas, concebemos que o letramento científico e crítico articula-se a um letramento digital ou, dito de outra forma, ao desenvolvimento explicitamente organizado de competências em letramento digital. De fato, numerosas informações passam por esses meios, e, ao contrário do que pode veicular um pensamento comum construído pelo conceito de nativo digital (PRENSKI, 2001), muitos trabalhos atualmente mostram que os jovens precisam ser formados para as especificidades desse tipo de leitura e de apropriação (LARDELLIER, 2017; FLUCKIGER, 2017, 2019; entre outros). Além disso, se se trata de passar essa mediação pela instituição escolar e universitária, também é necessário prever a formação de professores.

Nessa perspectiva, centrada no desenvolvimento do espírito crítico, da consciência cívica e do exercício da democracia, não se trata de se aculturar apenas aos aspetos tecnológicos, mas também a modos de (re)configuração dos discursos (ROSIER, 2020; LONGHI, 2017; entre outros), às questões de ethos e de 
postura (ROSIER, 2019), ou, ainda, de expressão da autoridade e de influências na Web (ver dossiê Autorité et Web 2.0 : approches discursives na revista Argumentation et Analyse du Discours, n. 26, 2021).

$* * * * * * * * * * * * * * * * * * * * * * * * * * * * * * * * * * * * * * * * * * * * * *$

Este dossiê articula e reúne pesquisadores alinhados à discussão central projetada, recortada sob diferentes olhares e perspectivas teóricas, aspecto que consideramos bastante positivo, sobretudo tendo em conta a complexidade dos fenômenos relacionados à desinformação e falsas notícias.

DÉBORA LIBERATO ARRUDA HISSA discute os fenômenos da desmediatização e da infodemia, em sua relação com a divulgação de notícias falsas como consequência da vulgarização de opiniões disruptivas propagadas pela cultura digital, que se assentam em orientações ideológicas, recriando e alimentando o antagonismo.

$\mathrm{O}$ artigo de GABRIEL GUIMARÃES ALEXANDRE toma como objeto o papel da "memória discursiva" - conceito tratado como importante para a formação do leitor em tempos de pandemia - em manchetes de duas agências de fact-checking, que desmentem notícias sobre covid-19 em mídias sociais.

Assumindo como objeto o fenômeno da desinfodemia no Brasil ELIARA SANTANA FERREIRA discute o papel de instâncias públicas federais e de veículos de comunicação alinhados ao presidente Jair Bolsonaro, na consolidação de um processo de desinformação sobre a covid-19.

Por meio da análise de manifestações do atual presidente do Brasil, Jair Bolsonaro, e posicionamentos construídos sobre elas, 
EMERSON DE PIETRI, TATIANE SILVA SANTOS e THIAGO MENA abordam estratégias discursivas de desestabilização dos sentidos e suas relações com mecanismos de manipulação de informações.

Tomando como corpus o discurso de abertura de Jair Bolsonaro em assembleia da ONU em 2020, MARIA ANGELA PAULINO TEIXEIRA LOPES e FERNANDA SANTANA GOMES analisam as posições axiológicas nele presentes.

SÉRGIO LUIZ BELLEI debruça-se sobre o conceito de "pós-verdade", por meio da discussão de novas interpretações do conto "Bartleby, o escrevente", de autoria de Herman Melville.

O texto de ANA CLÁUDIA BERTINI CIENCIA dedica-se à discussão acerca das competências de alunos de ensino médio para identificação de informação falsa em práticas sociais de leitura e escrita mediadas por mídias digitais.

A partir da reflexão sobre os fatores pragmáticos da textualidade na produção de fake news sobre a covid-19, NATÁLIA COÊLHO BAGAGIM, MARCELO SILVA DE SOUZA RIBEIRO e LUCINALVA DE ALMEIDA SILVA discutem o nível de formação crítica de leitores, considerada a grande circulação de publicações sobre a cura da covid-19 mediante insumos caseiros.

EULÁLIA LEURQUIN e CHLOÉ LEURQUIN, por meio da análise de postagens com conteúdo falso nas redes sociais em dois importantes momentos da vida brasileira, argumentam a favor da formação de leitores críticos.

Visando à formação do letramento crítico de estudantes do ensino médio, MARIANA GALDINO SANTANA apresenta e justifica um plano de ensino voltado à construção da leitura crítica e à formação de opinião a partir da recepção de "pós-fatos" que 
tomam como referente o Nordeste e o(a)s nordestino(a)s.

Encerra o dossiê a entrevista com JOHANNES ANGERMULLER realizada por LUCIANA SALAZAR SALGADO e LETÍCIA CLARES, com tradução de GUSTAVO PRIMO. Na entrevista, o linguista alemão discorre sobre questões atinentes aos discursos no contexto da comunicação hiperdigital.

A seção livre contempla um artigo e uma resenha. No artigo, FERNANDO MIRANDAARRAZ e FAGNER RIBEIRO SENA, por meio da análise do discurso do atual presidente do Brasil, Jair Messias Bolsonaro, promovem reflexão sobre Formação Discursiva e Memória Discursiva, na perspectiva da Análise do Discurso de linha francesa.

ANDRÉIA TEIXEIRA resenha o volume IV da Coleção de e-books, "Práticas discursivas em letramento acadêmico: questões em estudo", intitulado "Efeitos da covid-19 em práticas letradas acadêmicas", com organização de Juliana Alves Assis, Fabiana Komesu e Cédric Fluckiger. 
Referências

ARGUMENTATION et Analyse du Discours. Autorité et Web 2.0 : approches discursives [En ligne], n. 26, 2021. Disponível em: https://journals.openedition.org/aad/4929. Acesso em: 21 set. 2021.

ASSIS, J. A.; KOMESU, F.; FLUCKIGER, C. Em torno dos efeitos da covid-19 em práticas letradas acadêmicas. In: ASSIS, J. A.; KOMESU, F.; FLUCKIGER, C. (org.) Efeitos da covid-19 em práticas letradas acadêmicas. Belo Horizonte: Editora PUC Minas, 2020, v. 4, p. 9-31.

AUTHIER-REVUZ, J. Heterogeneidade(s) enunciativa(s). Tradução de Celene M. Cruz; João Wanderley Geraldi. Caderno de Estudos Linguísticos, Campinas, n. 19, 1990, p. 25-42.

AYALA, F. J. Introductory essay: the case for scientific literacy. In: World Science Report, Paris: UNESCO, 1996. Disponível em: https://unesdoc.unesco.org/ark:/48223/pf0000102930. Acesso em: 28 ago. 2021.

BENKLER, Y.; FARIS, R.; ROBERTS, H. Network Propaganda: Manipulation, Disinformation, and Radicalization in American Politics. New York: Oxford University Press, 2018. CASTELLS, M. Ruptura: a crise da democracia liberal. Trad.: Joana Angélica d'Avila Melo. Rio de Janeiro: Zahar, 2018.

CORRÊA, M. L. G. A inter-incompreensão polêmica e sua versão solipsista em práticas de leitura emergentes. ComHumanitas, v. 11, p. 68-81, 2020.

CORREAA, M. L. G. O modo heterogêneo de constituição da escrita. São Paulo: Martins Fontes, 2004.

COURTINE, J.-J. Análise do discurso político: o discurso comunista endereçado aos cristãos. São Carlos: EDUFSCAR, 2009. 
A formação do leitor no contexto da desinformação e das fake news: desafios para os estudos de letramentos na pandemia da covid-19 e além

EUROPEAN COMMISSION. A multi-dimensional approach to disinformation, 2018. Disponível em: https://ec.europa.eu/ digital-single-market/en/news/final-report-high-level-expertgroup-fake-news-and-online-disinformation. Acesso em: 26 ago. 2021.

FLUCKIGER, C. Innovations numériques et innovations pédagogiques à l'école. Recherches, p. 119-134, 2017.

FLUCKIGER, C. Une approche didactique de l'informatique scolaire. Rennes: Presses Universitaires de Rennes, 2019. (Collection Paideia).

FOUCAULT, M. A ordem do discurso. 24 ed. Tradução: Laura Fraga de Almeida Sampaio. São Paulo: Loyola, 2014.

FREIRE, P. Pedagogia do oprimido. Rio de Janeiro: Paz e Terra, 1987.

FREIRE, P. Pedagogia da autonomia: saberes necessários à prática educativa. São Paulo: Paz e Terra, 1996.

GEE, J. P. Literacy: from Plato to Freire. In: Social Linguistics and literacies: ideology in discourses. Londres: Taylor \& Francis, 1994. p. 27-48.

GALHARDI, C. P. et al. M. Fato ou Fake? Uma análise da desinformação frente à pandemia da Covid-19 no Brasil. Ciência \& Saúde Coletiva, Rio de Janeiro, v.25, p. 42014210, out. 2020. Disponível em: http://www.scielo.br/scielo. php?script=sci_arttext\&pid=S1413-81232020006804201\&lng= en\&nrm=iso. Acesso em: 26 ago. 2021.

ISLAM, M. S. et al. Covid-19-Related infodemic and its impact on public health: A global social media analysis. The American Journal of Tropical Medicine and Hygiene, 103(4), p. 16211629, 2020.

JENKINS, H.; FORD, S.; GREEN, J. Cultura da conexão. Tradução de Patrícia Arnaud. São Paulo: Aleph, 2014. 
JOHNS HOPKINS. Covid-19 Dashboard by the Center for Systems Science and Engineering (CSSE). Disponível em: https://coronavirus.jhu.edu/map.html. Acesso em: 22 ago. 2021. KAKUTANI, M. A morte da verdade: notas sobre a mentira na era Trump. Tradução de André Czarnobai e Marcela Duarte. Rio de Janeiro: Intrínseca, 2018.

KOMESU, F.; ALEXANDRE, G. G.; SILVA, L. S. A cura da infodemia? O tratamento da desinformação em práticas sociais letradas de checagem de fatos em tempos de Covid-19. In: RODRIGUES, D. L. D. I.; SILVA, J. Q. G. (org.). Estudos aplicados à prática de escrita acadêmica: colocando a mão na massa. Belo Horizonte: Editora PUC Minas, 2020. v. 3, p. 185-229.

KOMESU, F.; COSTA, J. R. P.; CIENCIA, A. C. Covid-19 e (des)informação: notas sobre o serviço brasileiro "Saúde sem Fake News" e seu leitor. (No prelo).

KOMESU, F.; DAUNAY, B.; FLUCKIGER, C. Littéracies numériques et désinformation: le rôle de l'enseignant dans le contexte d'infodémie. In: SCHEEPERS, C. (org.). Former à l'écrit, former par l'écrit dans le supérieur. Paris: DeBoeck, 2021. p. 255-267.

LACHANCE, J. L'éthos de l'adolescent dans les mondes numériques : le rôle des destinataires. Itinéraires, 2015. Disponível em: http://journals.openedition.org/itineraires/3156. Acesso em: 15 set. 2021

LARDELLIER, P. «Y » et digital natives, faux concepts et vrais slogans. Une lecture critique de deux « ressources sûres » de la doxa numérique. Hermès, La Revue, n. 78, p. 151-158, 2017.

LEA, M.; STREET, B. V. O modelo de "letramentos acadêmicos": teoria e aplicações. Tradução: Fabiana Komesu; Adriana Fischer. Filologia e Linguística Portuguesa, v. 16, n. 2, p. 477-493, 2014. 
LONGHI, J. Humanités, numérique : des corpus au sens, $\mathrm{du}$ sens aux corpus. Questions de communication, n. 31, p. 7-17, 2017. Disponível em: https://doi.org/10.4000/ questionsdecommunication.11039. Acesso em: 15 set. 2021.

MARTENS, B. et al. F. The digital transformation of news media and the rise of disinformation and fake news: an economic perspective. Seville: European Commission, Joint Research Centre, 2018. Disponível em: https://ec.europa.eu/ jrc/en/publication/eur-scientific-and-technical-research-reports/ digital-transformation-news-media-and-rise-disinformationand-fake-news. Acesso em: 26 ago. 2021.

McINTYRE, L. Post-Truth. Cambridge, Massachusetts: MIT Press, 2018.

MELL, L. À travers les hypostases du numérique dans l'enseignement supérieur: réflexion critique sur le développement de la culture et des compétences numériques. Lien social et Politiques, n. 81, p. 73-191, 2018.

MELLO, P. C. A máquina do ódio: notas de uma repórter sobre fake news e violência digial. São Paulo: Companhia das Letras, 2020.

McLAREN, P. L. Culture or Canon? Critical Pedagogy and the Political of Literacy. Harvard Educational Review, v. 58, n. 2, p. 213-234, 1988.

MIGUEL, L. F. Jornalismo, polarização política e a querela das fake News. Estudos em Jornalismo e Mídia, v. 16, n. 2, p. 4648, jul./dez. 2019. Disponível em: https://periodicos.ufsc.br/ index.php/jornalismo/article/view/1984-6924.2019v16n2p46. Acesso em: 26 ago. 2020.

NEWMAN, N. et al. Reuters Institute: Digital News Report 2021. London: Reuters Institute; University of Oxford, 2021. Disponível em: https://reutersinstitute.politics.ox.ac.uk/digitalnews-report/2021. Acesso em: 26 ago. 2021. 
NIELSEN, R. K.; GRAVES, L. New You Don't Believe: Audience Perspectives on FakeNews. Oxford: Reuters Institute for the Study of Journalism, 2017. Disponível em: https:// reutersinstitute.politics.ox.ac.uk/sites/default/files/2017-10/ Nielsen\%26Graves_factsheet_1710v3_FINAL_download.pdf. Acesso em: 26 ago. 2021.

OLIVEIRA, A. R.; BRASILEIRO, A. M. M.; ASSIS, J. A. Ser professor no Brasil nos tempos da Covid-19: o que mudou? Revista Virtual de Estudos da Linguagem, v. 18, p. 499-513, 2020.

\section{ORGANIZAÇÃO PAN-AMERICANA DE SAÚDE.}

Folha informativa Covid-19. Disponível em: https:// www.paho.org/pt/covid19. Acesso em: 26 ago. 2021. PANGRAZIO, L. What's new about "fake news"? Critical digital literacies in an era of fake news, post-truth and clickbait. Revista Páginas de Educación, Montevideo, v. 11, n. 1, p. 6-22, jun. 2018.

PÊCHEUX, M. Análise automática do discurso - AAD 69. In: GADET, F.; HAK, T. (org.). Por uma análise automática do discurso. Tradução de Bethania Mariani et al. Campinas: Editora da UNICAMP, 1990. p. 61-162.

PIOVEZANI, C.; CURCINO, L.; SARGENTINI, V. O discurso e as verdades: relações entre a fala, os feitos e os fatos. In: PIOVEZANI, C.; CURCINO, L.; SARGENTINI, V. (org.). Discurso e (Pós)Verdade. São Paulo: Parábola Editorial, 2021. p. 7-18.

POSSENTI, S. Ler: descrever e interpretar. In: SERRANI, S. (org.). Letramento, discurso e trabalho docente: uma homenagem a Angela Kleiman. Vinhedo: Editora Horizonte, 2010.

PRENSKY, M. Digital Natives, Digital Immigrants. On the Horizon, MCB University Press, v. 9, n. 5, 2001. 
REDE DE PESQUISA SOLIDÁRIA. Covid-19: Políticas públicas e as respostas da sociedade. Nota técnica n. 31, 22 maio 2021. Disponível em: https://redepesquisasolidaria.org/ wp-content/uploads/2021/05/boletimpps-31-22maio2021.pdf. Acesso em: 26 ago. 2021.

RIBEIRO, A. E.; VECCHIO, P. M. M. (org.). Tecnologias digitais e escola. São Paulo: Parábola, 2020.

ROQUE, T. O negacionismo no poder: como fazer frente ao ceticismo que atinge a ciência e a política. Piauí, edição 161, fev. 2020. Disponível em: https://piaui.folha.uol.com.br/materia/onegacionismo-no-poder/. Acesso em: 26 ago. 2021.

ROSIER, L. Ethnographie linguistique d'un « idiolecte " sur Facebook : identité, ethos et posture numérique, 2019. Disponível em: http://researchgate.net/publication/333984647 Etnographie_linguistique_d'un_idiolecte_sur_Facebook_ identite_ethos_et_posture_numérique. Acesso em: 15 set. 2021. ROSIER, L. Reconfigurations des formes canoniques du discours rapporté en milieu numérique : quelques exemples remarquables de discours directs. E-rea [En ligne], 17.2, 2020. Disponível em: http://journals.openedition.org/erea/9742. Acesso em: 15 set. 2021.

SIAROVA, H.; STERNADEL, D.; SZÖNYI, E. Research for CULT Committee: Science and Scientific Literacy as an Educational Challenge. Brussels: European Parliament, 2019. Disponível em: https://www.europarl.europa.eu/RegData/ etudes/STUD/2019/629188/IPOL_STU(2019)629188_EN.pdf. Acesso em: 26 ago.2020.

STREET, B. V. Literacy in theory and practice. Cambridge: Cambridge University Press, 1984.

STREET, B. V. Letramentos sociais. Tradução de Marcos Bagno. São Paulo: Parábola, 2014. 
TANDOC Jr., E. C.; LIM, Z. W.; LING, R. Defining "Fake News". Digital Journalism, v. 6, n. 2, p. 137-153, 2018.

VISCARDI, J. M. Fake News, Verdade e Mentira sob a ótica de Jair Bolsonaro no Twitter. Trabalhos em Linguística Aplicada, Campinas, v. 59, n. 2, p. 1134-1157, ago. 2020. Disponível em: http://www.scielo.br/scielo.php?script=sci_arttext\&pid=S010318132020000201134\&lng=en\&nrm=iso. Acesso em: 26 ago.2021.

VOSOUGHI, S.; ROY, D.; ARAL, S. The spread of true and false news online. Science, 359, p. 1146-1151, 2018. 